\title{
ENDOMETRIAL DIFFERENTIATION IN THE PREGNANT SOW AND THE NECROTIC TIPS OF THE ALLANTOCHORION
}

\author{
P. F. FLOOD \\ Department of Veterinary Anatomy, University of Bristol, \\ Bristol BS1 5LS
}

(Received 4th October 1972)

Hughes (1927) suggested that the degenerate extremities of the pig's allantochorion, the necrotic tips, may discourage the formation of vascular anastomoses between one conceptus and its neighbours and may be important in controlling the incidence of freemartinism in the pig. The gross appearance of the allantochorionic extremities has been described from 39 days' gestation onward (Ashdown \& Marrable, 1967) and histologically the necrotic tip has been shown to be an envelope of closely packed collagenous lamellae lacking both trophoblast and allantoic endoderm (Marrable, 1968). The endometrium adjacent to the necrotic tips is very pale, covered with mucus (Lesbre, 1910), contains numerous lymphocytes and plasma cells (Marrable, 1968) and has an epithelium which is rich in glycogen (Lovell \& Garm, 1965). The present observations concern the earlier development of the necrotic tips, the associated zones of modified endometrium, and those areas of the uterus which remain unoccupied or become so as a result of early embryonic loss.

Twenty-eight, mature, Large White or Landrace sows were served on the 1st and 2nd days of oestrus and killed at known stages of gestation. The day of second service was regarded as Day 0. In addition, uteri from twenty-three pregnant sows of unknown history were obtained. The gestational ages were estimated from the mean embryonic length according to the data of Marrable \& Ashdown (1967). The uteri were opened along the mesometrial border to allow examination of the embryos and the related endometrium. Tissue samples were fixed in Helly's fluid and embedded in esterwax. Sections cut at 5 or $7 \mu \mathrm{m}$ were stained in haematoxylin and eosin, haematoxylin and PAS, or PAS alone.

Before the formation of the necrotic tips, the surface of the allantochorion was uniformly vascular (Pl. 1, Fig. 1) but between 27 and 30 days' gestation (Table 1), the great majority of embryos began to show small irregular areas of discolouration at the poles; these spread rapidly to form a clearly defined, dull brown cap at each end of the allantochorion. The cap had no active vasculature although the paths of the original vessels were still discernible as brownish lines (Pl. 1, Fig. 2); thus, the necrotic tips of neighbouring embryos normally formed a 3- to 8-cm wide, avascular region between one conceptus and the next. The annular constriction which forms at the junction of the 
healthy and necrotic tissue (Ashdown \& Marrable, 1967) was not present when necrosis first occurred but was foreshadowed by a slight puckering of the allantochorion at 35 days and was well-developed by Day 42 .

From its beginning, the degeneration of the allantochorionic extremities was accompanied by loss of trophoblast and allantoic endoderm and condensation of the mesenchymal component, as described in the definitive state (Marrable, 1968). The vascular endothelium became indistinct and the nucleated erythrocytes within the vessels became aggregated and eventually lost their cytoplasm. The original vascular channels were then marked by tracts of densely packed nuclei (Pl. 2, Fig. 5). Secondary extensions of the terminal necrotic zone frequently occur later in gestation (Ashdown \& Marrable, 1970) and when these develop after the disappearance of nucleated erythrocytes from the circulation, no tracts of nuclei are found. These observations do not support the designation 'lymphoid' previously applied to these structures (Marrable, 1968).

Table 1. Percentage of allantochorionic extremities showing necrosis at different stages of gestation in the sow

\begin{tabular}{l|cccc}
\hline & \multicolumn{4}{|c}{ Gestational age (days) } \\
\cline { 2 - 4 } & 27 to 29 & 30 to 32 & 33 to 35 \\
\hline $\begin{array}{l}\text { Percentage of extremities } \\
\text { showing necrosis }\end{array}$ & 15 & 77 & 97 \\
No. of litters examined & 6 & 9 & 6 \\
\hline
\end{tabular}

The endometrium of non-pregnant uteri and of uteri examined before 19 days' gestation was completely uniform along its length but by 22 days' gestation, the endometrium adjacent to the developing allantois was distinctly hyperaemic compared with the remainder which retained the delicate pink colour of dioestrus and early pregnancy. During the following week, the endometrium of the placental zones increased in vascularity while that adjacent to the poles of the allantochorion, the interlocular endometrium, became very pale, translucent and thickened by oedema. The interlocular zones were usually 3 to $8 \mathrm{~cm}$ wide and were sharply demarcated from placental zones

\section{EXPLANATION OF PLATE 1}

Fig. 1. Both extremities of a single allantochorion at 29 days' gestation in a sow. A network of vessels extends over the entire surface. $\times 0.5$.

Fig. 2. One extremity of an allantochorion at 34 days' gestation showing a recently formed necrotic tip. $\times 0.64$.

Fig. 3. Part of the endometrial surface at 33 days' gestation. The dark areas to left and right are parts of the placental zones associated with two neighbouring embryos. The pale transverse band of interlocular tissue is sharply demarcated along the lines arrowed. $\times 0.5$.

Fig. 4. Part of the endometrial surface at 35 days' gestation. The broad, dark area on the left is part of the placental zone. The narrower area on the right is an unoccupied section of uterus and between the two is a pale transverse band of interlocular tissue. $\times 0.5$. 
PIATTE 1

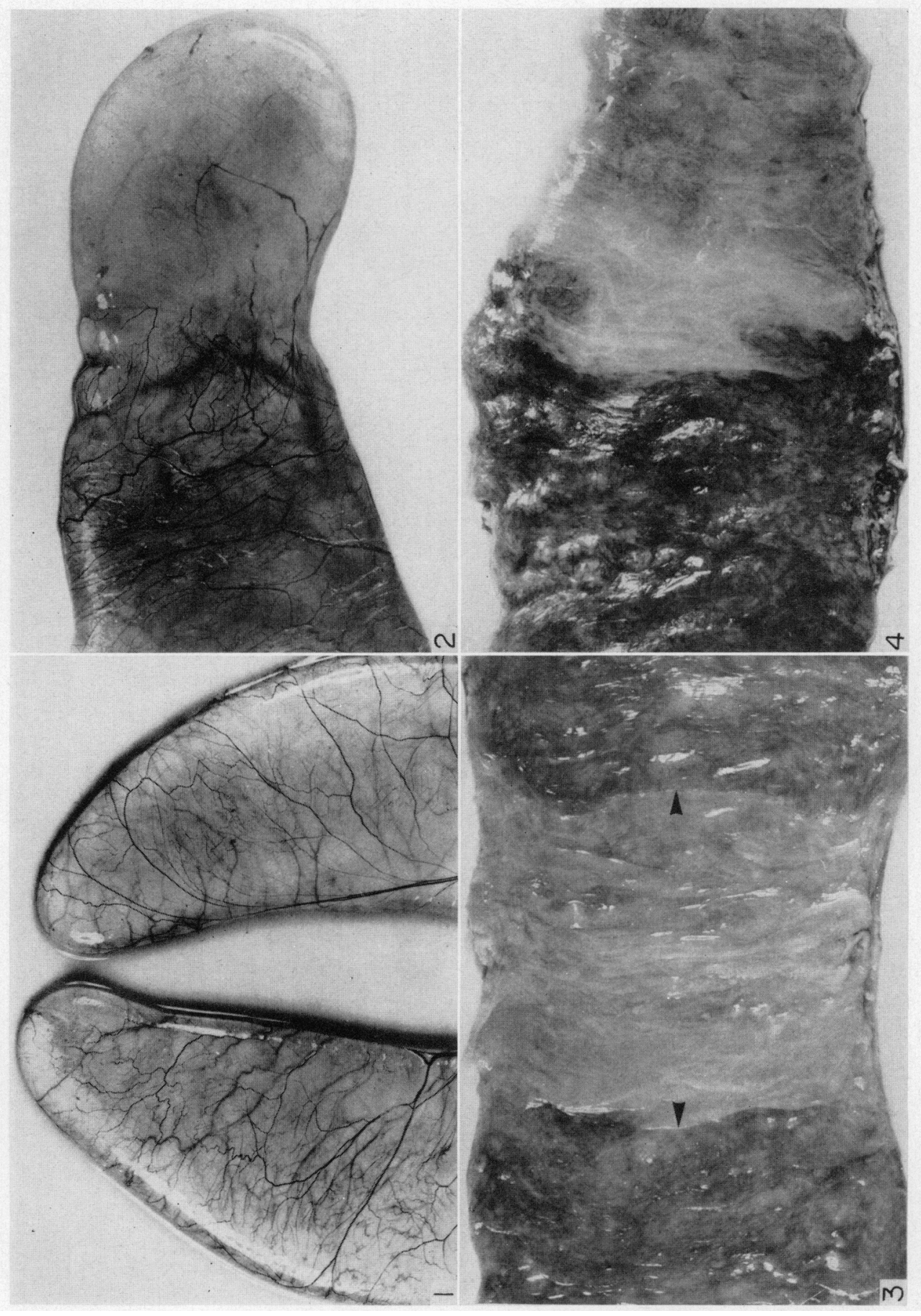

(Facing 1,540 ) 


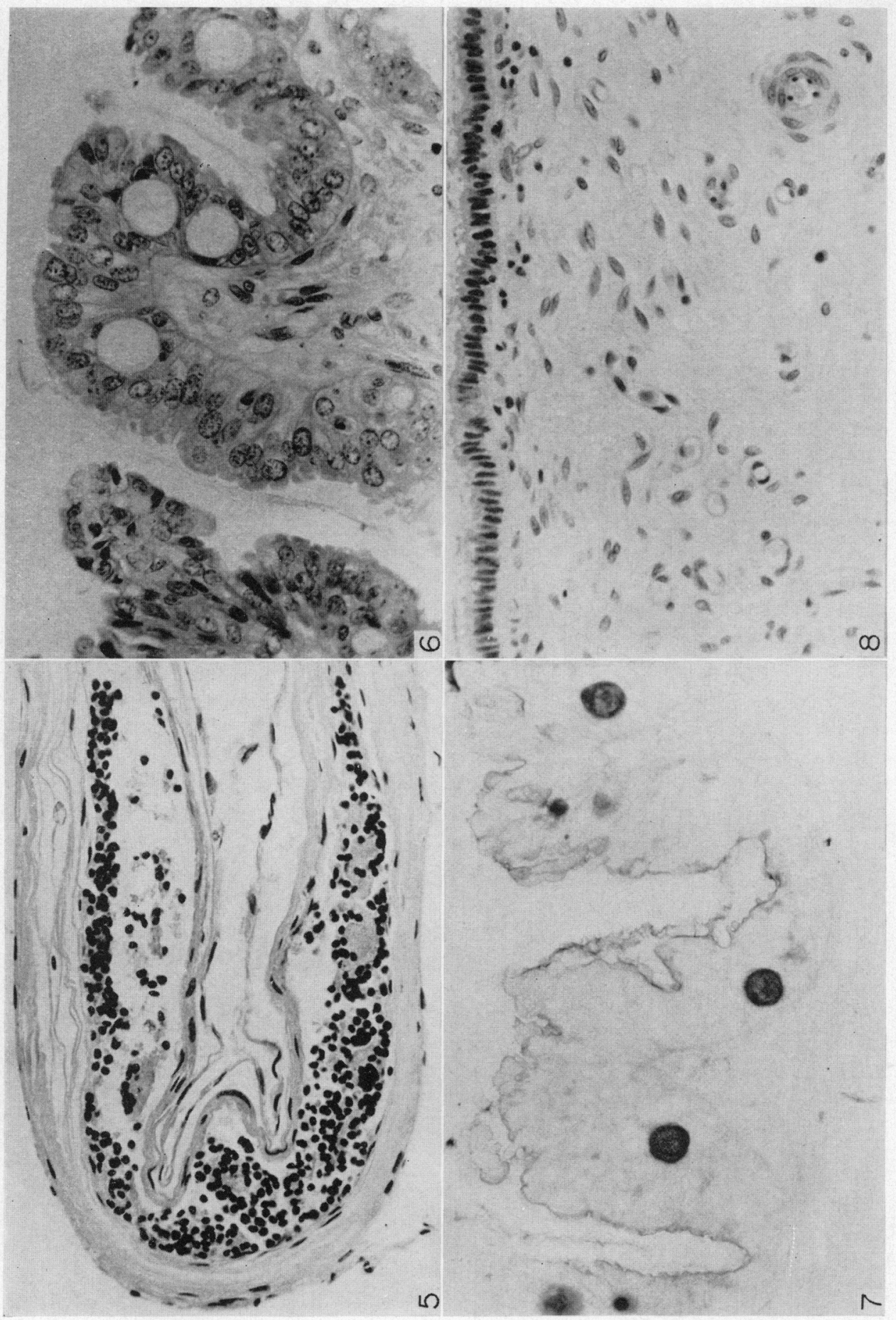

(Facing p. 541) 
(PI. 1, Fig. 3). Interlocular tissue was not only present between the great majority of embryos but was also found at the ovarian end of the conceptus nearest each ovary, and around the internal cervical ostium.

The epithelium of the interlocular zone had a characteristic feathery outline, transverse folds and a high columnar form. The nuclei were large, oval and vesicular and the surrounding cytoplasm was plentiful and less basiphilic than that of the placental zones. Between 29 and 36 days' gestation, the epithelium contained numerous large vesicular structures, the contents of which were virtually unstained by haematoxylin-eosin (PI. 2, Fig. 6) but stained intensely with PAS and were resistant to digestion by saliva (Pl. 2, Fig. 7). During this period, the vesicles increased in size, migrated towards the uterine lumen and discharged their contents into it. The epithelial cells were also rich in a saliva-soluble PAS-positive material which was presumed to be glycogen. After 40 days' gestation, vesicles were rare and the folded arrangement of the epithelium was more regular than before. While large numbers of cells were being sloughed into the lumen from the rugae, copious mucus secretion was evident in the fossae.

The interlocular uterine glands were poorly developed compared with those of the placental zones and in sections, they appeared less frequent, smaller in diameter and had a lower epithelium. The endometrial vasculature was also greatly reduced and the subepithelial capillaries, which were plentiful during dioestrus and early pregnancy and which formed an almost unbroken layer in the placental zones, were completely absent. The subepithelial connective tissue stained only lightly and showed the oedema previously noted macroscopically. Large numbers of lymphocytes and plasma cells were present in the lamina propria but did not seem to be more numerous than they were in the placental zones. Eosinophils were found in large concentrations in seven of forty samples of interlocular tissue, but were never seen in the placental or unoccupied parts of the endometrium.

Unoccupied sections of uterus failed to differentiate into either placental or interlocular forms but remained only moderately vascular, thinly covered with mucus and without oedema (Pl. 1, Fig. 4). The surface epithelium had no regular pattern of folds and was comparatively smooth, very low and had small, oval, uniformly stained nuclei with irregular outlines (Pl. 2, Fig. 8).

\section{EXPLANATION OF PLATE 2}

FIG. 5. Part of the wall of a necrotic tip of a sow's allantochorion at 31 days' gestation, showing the path of a blood vessel in longitudinal section. The allantochorion is folded and its uterine surface is innermost. The trophoblast and allantoic endoderm are lacking, the fibroblast nuclei are pycnotic and the embryonic erythrocytes have lost almost all their cytoplasm. H \& E. $\times 290$.

FIG. 6. The uterine epithelium of the interlocular zone at 35 days' gestation, showing the feathery outline and large, open nuclei characteristic of the region and four mediumsized vesicular structures. Mucus secretion is evident in the depths of the epithelial fossae and subepithelial capillaries are absent. H \& E. $\times 290$.

Fig. 7. Same material as in Fig. 6. Saliva digestion. PAS. The contents of the vesicular structures are intensely stained. $\times 290$.

Fra. 8. The endometrium of an unoccupied part of the pregnant uterus at 31 days' gestation. The epithelium is low and the nuclei are irregular in outline and uniformly basiphilic. H \& E. $\times 290$. 
The cytoplasm was scanty and more basiphilic than that of the interlocular zones and contained numerous PAS-positive granules. The uterine glands were like those of the interlocular zones but subepithelial capillaries were plentiful though less numerous than in the placental areas.

Direct observations on the uterine epithelium suggested that there were marked differences in mitotic rate between the endometrial zones. Using only well-preserved material, 1000 cells were examined in each of twenty-six samples of placental zone, nineteen samples of interlocular zone and twelve samples of unoccupied uterus. The mean mitotic rate for the placental zone was $4 \cdot 19$ (S.D. 4.9) divisions $/ 10^{3}$ cells, that for the interlocular zone was $20 \cdot 11$ (S.D. 4.51) while that for the unoccupied uterus was only $0 \cdot 17$. The rapid cell division observed in the interlocular zones was consistent with the rate of cell loss into the uterine lumen.

The stimulus leading to the formation of the placental and interlocular zones is obscure, though it is apparently of embryonic origin since no zonation is discernible in the non-pregnant uterus and no one litter shows the same pattern of zones as another. Vesicles similar to those seen in the interlocular zones are also present in the uterine epithelium of the irregular areolae (Amoroso, 1955; Crombie, 1972) but not in that of the regular areolae. With this exception, it seems that, wherever the pig's uterine epithelium lies within about $0.5 \mathrm{~cm}$ of the conceptus, but is not directly attached to it, it takes on the appearance of the interlocular zone. The initial differentiation of the endometrium and the formation of the allantochorion coincide in time. At 19 days' gestation, no endometrial zonation was seen and the allantois was less than $5 \mathrm{~cm}$ in length and had fused to the chorion over a very limited area. At 22 days, however, the placental zones were clearly distinguishable and the allantois was over $15 \mathrm{~cm}$ in length and had fused to the chorion over a broad equatorial band.

The reduced vascularity of the interlocular zones might be expected to cause a local interference with the nutrition of the extremities of the conceptus and this effect is likely to be exacerbated by the absence of subepithelial capillaries, increase in epithelial height and accumulation of mucus in the uterine lumen. The interlocular zones may, therefore, be involved in the formation of the necrotic tips.

Ashdown \& Marrable (1967) doubted if the necrotic tips influence the fusion of adjacent placentae in the latter half of gestation, but the present study suggests that they tend to inhibit interembryonic vascular anastomosis between 29 and 50 days. This may be a critical period since it immediately follows histological sex differentiation (Black \& Erickson, 1968).

I am very grateful to $\operatorname{Dr} \mathrm{A}$. W. Marrable for his advice and interest, Mrs Jill Clement and Miss Christine Collings for the histological work and $\mathrm{Mr}$ Derek Telling for the photography.

\section{REFERENCES}

Amoroso, E. G. (1955) The comparative anatomy and histology of the placental barrier. In: Trans. 1st Conf. on Gestation, Princeton, N.J., March 1954, p. 119. Ed. L. B. Flexner. Josiah May Jr Foundation, New York. 
Ashdown, R. R. \& Marrable, A. W. (1967) Adherence and fusion between the extremities of adjacent embryonic sacs in the pig. F. Anat. 101, 269.

Ashdown, R. R. \& MARRABLE, A. W. (1970) The development of the embryonic membranes in the pig: observations on afterbirths. Res. vet. Sci. 11, 227.

Black, J. L. \& ERICKson, B. H. (1968) Oogenesis and ovarian development in the prenatal pig. Anat. Rec. 161, 45.

CROMBIE, P. R. (1972) Morphology and ultrastructure of the pig's placenta throughout pregnancy. Ph.D. thesis, University of Cambridge.

Hughes, W. (1927) Sex intergrades in foetal pigs. Biol. Bull. mar. biol. Lab., Woods Hole, 52, 121.

Lesbre, F. X. (1910) Sur les annexes foetales du porc. 7. Méd. vét. Zootech. 61, 196.

Lovelz, J. E. \& GarM, O. (1965) Histochemical studies on the uterus and foetal membranes of the sow during early pregnancy. In: Proc. 5th Int. Cong. Anim. Reprod. A.I., Trento 1964, Vol. V, p. 170 .

Marrable, A. W. (1968) The ischaemic extremities of the allantochorion of the pig and their relation to the endometrium. Res. vet. Sci. 9, 578.

MARRable, A. W. \& Ashdown, R. R. (1967) Quantitative observations on pig embryos of known ages. F. agric. Sci., Camb. 69, 443. 